\title{
Families of patients with polytrauma: Understanding the evidence and charting a new research agenda
}

\author{
Joan M. Griffin, PhD; ${ }^{1-2 *}$ Greta Friedemann-Sánchez, PhD; ${ }^{3}$ Carmen Hall, PhD, RN; ${ }^{1}$ Sean Phelan, MPH; ${ }^{4}$ \\ Michelle van Ryn, PhD, MPH \\ ${ }^{1}$ Center for Chronic Disease Outcomes Research, Department of Veterans Affairs (VA) Health Services Research Center \\ of Excellence, Minneapolis VA Medical Center, Minneapolis, $M N ;{ }^{2}$ Department of Medicine, Division of General \\ Internal Medicine, University of Minnesota Medical School, Minneapolis, MN; ${ }^{3}$ Hubert H. Humphrey Institute of Public \\ Affairs, University of Minnesota, Minneapolis, $M N ;{ }^{4}$ Department of Epidemiology and Community Health, University \\ of Minnesota School of Public Health, Minneapolis, MN; ${ }^{5}$ Department of Medicine, Division of Family Medicine and \\ Community Health, University of Minnesota Medical School, Minneapolis, MN
}

\begin{abstract}
Although research shows that caring for a family member with chronic disease or disability can cause significant distress for caregivers, it also shows that families that function well and adequately support patients can improve the quality of life and health outcomes for their ill or disabled family member. Currently, little knowledge exists about how families function and cope after a loved one has sustained polytrauma, the multiple traumatic injuries that often include traumatic brain injury (TBI). We summarize the polytrauma and TBI research about family needs during rehabilitation and recovery, describe current efforts to improve family-centered care, and detail approaches for understanding family resilience and the longterm consequences of injuries on families. We conclude with recommendations for future research in inpatient and outpatient settings where evidence has been limited for families of patients with TBI and is nonexistent for families of patients with polytrauma. Understanding many of these issues will help to better inform families of policies for benefits and resources and help researchers and clinicians plan for appropriate interventions.
\end{abstract}

Key words: caregiving, families, Family Care Map, information needs, polytrauma, rapid assessment process, recovery, rehabilitation, resilience, stress, traumatic brain injury.

\section{INTRODUCTION}

As of December 2008, more than 38,000 servicemembers have been killed or wounded in action in Operation Iraqi Freedom (OIF) and Operation Enduring Freedom (OEF); thousands of those were wounded by blasts [1]. The frequency, intensity, and force from blast shock waves, flying debris from bomb fragments and

\footnotetext{
Abbreviations: DOD = Department of Defense, FCM = Family Care Map, OEF = Operation Enduring Freedom, OIF = Operation Iraqi Freedom, PRC = Polytrauma Rehabilitation Center, PT/BRI = Polytrauma/Blast-Related Injury, QUERI $=$ Quality Enhancement Research Initiative, RAP = Rapid Assessment Process, $\mathrm{TBI}=$ traumatic brain injury, $\mathrm{VA}=$ Department of Veterans Affairs, VBA = Veterans Benefits Administration, VHA $=$ Veterans Health Administration, VR\&E $=$ Vocational Rehabilitation and Employment, WG = working group.

*Address all correspondence to Joan M. Griffin, PhD; Center for Chronic Disease Outcomes Research, Minneapolis VA Medical Center, One Veterans Drive, Minneapolis, MN 55417; 612-467-4232; fax: 612-725-2118.

Email: joan.griffin2@va.gov

DOI:10.1682/JRRD.2008.08.0104
} 
nearby objects, blast wind, and other caustic agents often cause polytraumatic injuries-injuries to multiple body systems and organs [2]. Traumatic brain injury (TBI) is one of the most common injuries associated with blasts. In fact, recent reports suggest that of U.S. servicemembers exposed to blasts, 60 percent have a TBI [3-4]. The prevalence of TBI among OIF/OEF servicemembers is so high that it is now considered the "signature injury" of the conflicts [3]. Those who survive blasts and have a TBI as part of their polytrauma usually require intense rehabilitation to optimize functional outcomes.

Research on patients with TBI, stroke, dementia, and cancer suggests that their family members are significantly distressed [5-7] and that family functioning and support can predict patient quality of life and health outcomes [8-9]. Caring for a person with war-related polytrauma has been reported to be qualitatively different than caring for a person with only a TBI because the number of simultaneous injuries is higher and the nature of the injuries and their sequelae are more complex $[2,10]$. Little knowledge exists, however, about how families function after a servicemember has sustained polytrauma. Families caring for those severely wounded in war may, in fact, face contextually different challenges in how they function, including how they manage the social perceptions attached to providing care and support, the stigma often attached to disability and injuries, the changing role from a military to a civilian family, and the unique resources they use to cope with these challenges. What we know is that many polytraumatic injuries are so severe that patients require some degree of long-term caregiving and support from family, friends, and sometimes paid healthcare providers to perform daily activities, reintegrate into the community, and coordinate their ongoing health services and benefits. As injured patients shift from acute care to chronic and long-term care, caretaking responsibilities often shift from institutionally provided formal care to family-provided informal caregiving. New responsibilities and shifting roles often result in significant challenges for families. However, little systematic evidence exists regarding these challenges, and we have huge gaps in our understanding of the information, resources, and services families need to cope and function as their injured loved one recovers, rehabilitates, and reintegrates into the community.

Because research on blast-related polytrauma is relatively new, it draws heavily from the literature about TBI to guide both research and practice. Most of what we know about family functioning and TBI is limited to how families function during inpatient, acute, or subacute care, usually covering the time period from injury to 2 years postinjury. Little knowledge exists about family outcomes 3 years postinjury.

In this article, we use five sources to paint a picture of our knowledge regarding families of patients with war-related polytrauma, current efforts to address gaps in research and clinical practice, and research questions that remain unanswered. First, drawing from a study on the perspectives of specialists on polytrauma rehabilitation, we discuss the role families of patients with polytrauma play during the recovery and early rehabilitation processes. Second, drawing from the literature on TBI, we review what we know about the information families need and the most appropriate timing for information delivery in both inpatient and outpatient settings. Third, we describe a current endeavor to address gaps in family care during inpatient rehabilitation using a Family Care Map (FCM), a Web-based family resource guide for providers and families of patients in rehabilitation. Fourth, we review the dominant model of how stress affects family systems and how the literature considers family resiliency to stress. Fifth, we describe the background and purpose of an upcoming nationwide caregiver survey that will describe the long-term caregiving experience and its relationship to patient, family, and caregiver outcomes. We conclude by describing other gaps in research that need to be addressed to optimally and efficiently support family caregivers of servicemembers with polytrauma.

\section{BACKGROUND ON FAMILY INVOLVEMENT IN INPATIENT POLYTRAUMA REHABILITATION}

To date, little research exists on the families of patients with polytrauma and it is unclear whether the demands and challenges faced by these families differ significantly from those in the most comparable situation, families caring for patients with only TBI. Therefore, we first briefly describe the polytrauma system of care to provide a context for what families confront, and we summarize findings from a qualitative study of polytrauma providers on family information needs.

In 2005, the Department of Veterans Affairs (VA) designated four VA rehabilitation sites with expertise in comprehensive interdisciplinary rehabilitation for TBI as Polytrauma Rehabilitation Centers (PRCs) in response to 
the complex and unique rehabilitation needs of those severely injured in OIF/OEF [11]. Before this official designation, these TBI lead sites had been working closely with the Department of Defense (DOD) through a multisite collaboration called the Defense and Veterans Brain Injury Center. The PRCs (located in Minneapolis, Minnesota; Tampa, Florida; Palo Alto, California; and Richmond, Virginia) already had experience delivering healthcare to active duty personnel with TBI and coordinating healthcare across the DOD and VA care systems. However, the majority of the patients receiving inpatient TBI rehabilitation before OIF/OEF were veterans with TBI sustained in the United States from motor vehicle crashes, assaults, and falls. Because the PRCs new charge was to provide care for those with war-related polytrauma, including TBI, they were required to restructure how they provided their care for different types of injuries [10,12]. During this same period, the VA Health Services Research and Development Service established a Polytrauma/Blast-Related Injury (PT/BRI) Quality Enhancement Research Initiative (QUERI) Center to promote successful rehabilitation, psychological adjustment, and community reintegration for individuals with PT/BRIs. As part of its mission, the PT/BRI QUERI works to identify key gaps in the research evidence base needed to establish best practices for providing optimal PT/BRI care; prioritizes additional research to address these gaps; and supports these research efforts to build a bridge between research, clinical practice, and outreach services.

One of the key gaps initially identified by the PT/BRI QUERI was that the clinical challenges and needs for patients with polytrauma and their families were not well documented. Clinicians in the PRCs are uniquely suited to provide insight into this new and distinct group of patients and their families. Between February and July 2006, Friedemann-Sánchez et al. interviewed 56 providers with different clinical disciplines from the four PRCs [10]. They used a Rapid Assessment Process (RAP) methodology that included semistructured interviews, observation, and a field liaison to (1) describe and summarize typical family experiences before, during, and after receiving care in a PRC and (2) assess common needs identified by providers [10].

The RAP results indicated that the role of families is critical in all stages of polytrauma rehabilitation and recovery. During the current conflicts in Iraq and Afghanistan, the role of families of injured servicemembers has become significantly more active and integrated in their loved one's care. For those injured in theater, the involvement of families often starts soon after the servicemember is injured. Families frequently join patients at medical facilities in Germany and stay by their side as they transition from Germany to a DOD military treatment facility in the United States, and then to inpatient rehabilitation services, often at a PRC. Assisted by case managers, families help patients transition from one system of care to the next and navigate the administrative maze of Federal healthcare and financial benefits while they simultaneously deal with their own grief and loss and strive to come to terms with their loved one's injuries and the long-term implications for their family.

Healthcare providers interviewed for the RAP study reported how family involvement has changed as injured servicemembers return from war. They described the new challenges of providing "family-centered care" without any specific training, as well as uncertainty about what information to communicate to families and how to provide it. Providers also voiced concern that little information existed for them to share with families after discharge from the PRC, when the family's critical and active role of caregiving continues.

\section{ADDRESSING FAMILY AND CAREGIVER INFORMATION NEEDS}

The RAP study identified two significant needs to better serve families: (1) a concise summary of research on information needed by families and caregivers of patients and (2) guidelines to standardize family care across facilities and among providers within each PRC to optimize the most appropriate and consistent forms of communication to support information and emotional needs of families.

In the next two sections, we describe existing efforts to meet the needs identified in the RAP study. First, we summarize a recent narrative review of inpatient and outpatient information needs for family caregivers of patients with TBI. Second, we describe efforts to design, develop, and implement the FCM, a Web-based inpatient clinical practice tool designed to optimize family care and facilitate caregiver-provider communication during acute rehabilitation.

\section{Literature Review of Family Caregiver Information Needs}

Previous studies have identified the importance of resources needed to help caregivers and families cope 
effectively with a loved one's illness. Seeking information, for example, has been shown to have a protective effect on caregivers of patients with dementia [13-14]. Other studies have shown that receiving information is a mechanism that aids caregivers of critically ill patients in coping with their crisis by reducing stress, anxiety [1519], and uncertainty [15]. Research efforts in TBI have primarily focused on identifying family and caregiver demands rather than on identifying effective strategies for coping, such as information-seeking [20], but the information likely has the same effect on caregivers of patients with polytrauma as it does on caregivers of patients with dementia.

Our recent literature review focused on studies and review articles with the theme of information needs, education needs, caregiver-provider communication strategies, communication content, or timing of receipt and delivery of information for family caregivers of patients with TBI [21]. Fifty articles addressing family caregivers' information needs were identified and reviewed. We used Academic Search Premier, MEDLINE, and Psyc-INFO electronic databases to identify articles and citations. We then used key articles retrieved from these sources to identify additional publications. Of the 50 identified, only 19 were peer-reviewed; written in the English language; and included family caregivers' information needs, education needs, caregiver-provider communication strategies, communication content, or delivery of information and timing of receipt [21]. We summarized this literature by the (1) type of information needed, (2) appropriate timing for providing key information, (3) best ways to communicate information, and (4) gaps relevant to polytrauma.

\section{Type of Information Needed}

Most studies addressing information needs have focused on families' overall needs during inpatient care and on the type of information needed. Content areas of information in quantitative studies include health and medical information, problems in cognition/thinking, caring strategies for patients with traumatic injuries, and recognizing changes in the patient's medical status [2225]. Content areas in qualitative studies include clear, timely, and accurate information on diagnosis; treatment plans; prognosis and course of recovery; best- and worstcase scenarios; reasons for and results of diagnostic studies; specific hospital equipment use; medications; rationale for treatments; and possible patient behavior changes [26-28]. Caregivers also want to understand the purpose of rehabilitation [29], how rehabilitation facilitates recovery [30], and the effect that caring for a patient with TBI has on family relationships [31]. Information on community support, financial assistance, and self-care is needed as well [29,32-33].

\section{Appropriate Timing for Providing Key Information}

Most of the literature available focuses on information in the inpatient setting $[26,28]$. Although research is limited, qualitative data suggest that the information needs of families during inpatient care are different from those needed in the outpatient setting. Providing information before discharge, however, is complex because families may not know what questions to ask, what information they will need after discharge, or what problems they may face after discharge. Thus, providing information to families after patients have returned to the community may be best [26,34]. Studies have shown that families perceive that rehabilitation providers did not prepare them for the transition home because they typically do not recall information provided at discharge, partly because it is not relevant at the time [34]. Aitken et al. suggest an exit interview and a 6-week postdischarge follow-up call to capture information needs as they arise [26]. Because caregiver distress and worsening family functioning are often associated with behavioral and affective symptoms of TBI, information should possibly be provided regularly for several years postinjury [31].

Holland and Shigaki propose that information be presented at three phases: subacute, acute, and during outpatient rehabilitation (postdischarge) [29]. They provide a compendium of materials, which were later updated for pediatric patients with TBI [35], to reflect recommendations by caregivers [34].

\section{Best Ways to Communicate Information}

Two themes emerged from the literature on how providers can best communicate information to families and caregivers of patients with TBI: information presentation and information format.

All studies were specific to the inpatient setting. One key finding was that family stress interferes with the ability to receive and comprehend information, so finding ways to present information in the least stressful way is critical [33-34,36]. For instance, Bond et al. suggest information be provided by a designated healthcare provider to reduce stress and assure message consistency [27]. Others recommend presenting information empathetically using simple 
language [26,28], and when possible, written information should be presented with visual aids that families can use for future reference [28].

To make comprehensive information accessible to families and caregivers, several studies recommend using multiple formats, such as verbal, written, video, and the Internet [29,36-37]. No articles have addressed the need for cultural- or sex-sensitive informational materials, and few studies have tested the effectiveness of any specific educational program or compared different forms of communication.

\section{Gaps Relevant to Polytrauma}

Although much of the knowledge on TBI is likely to be generalizable to polytrauma, the information needs of caregivers of patients with polytrauma may be distinct because the context of the injuries and the amount and type of medical information required are more vast and complex and because of the number of injuries and their severity. Similarly, administrative information is complex because patients are involved in two, or sometimes three, healthcare and benefit systems, including the DOD, VA [10], and private hospitals or clinics in their communities. Research is needed to assess the specific information needs of caregivers who face such complexities. Furthermore, little research has been conducted to determine the information needs of families based on severity of injuries, to determine the best timing and approach to communicate information based on the patient's level of cognitive functioning, or the best training for providers on communicating with families who are grieving or angry about the patient's condition. The RAP study also reports that family caregivers respond and adjust differently depending on family composition and kinship to patient [10]. No research exists on polytrauma or TBI that addresses different information needs of family members according to sex.

In summary, little research has been conducted on how best to communicate with families of patients with TBI, especially after inpatient discharge and in outpatient settings. Moreover, intervention studies that test the effectiveness of communication strategies for families and caregivers are almost entirely absent from the literature [7]. These same gaps, therefore, also exist for caregivers of patients with polytrauma. Currently, no evidence-based guidelines exist about the best practices for communication and education to support the adaptation and adjustment of families of patients with poly- trauma across the continuum of treatment, rehabilitation, and lifelong services.

\section{Polytrauma Rehabilitation Center Family Care Map}

In addition to identifying the need for a summary of research on information needed by families and caregivers of patients, the RAP study identified the need to standardized family care across facilities and among providers within each PRC [10]. Understanding that families commonly assume prominent roles in the care of loved ones with chronic illnesses and disabilities [38] has brought increased attention to and emphasis on developing familycentered care [39]. This attention is especially true in clinical settings such as intensive care units and neonatal intensive care units where providers face the challenges of meeting the information and emotional support needs of distressed family members while treating patients with severely compromised health for whom treatment outcomes are highly uncertain [40-43].

\section{Overview of Family Care Map}

Using a framework with standardized descriptions of the clinical course and specific phases, the FCM provides a consistent approach and the vocabulary to describe the clinical signs for each phase of the rehabilitation plan and recommends how family members can match their communication and behavior to the current phase.

To date, no empirically based best practices exist for providing family-centered care. To provide consistent, high-quality, standardized care and encourage possible best practices, the PT/BRI QUERI collaborated with PRC staff and family-centered care experts to develop the FCM. The FCM is a Web-based clinical practice tool available to patients in the PRC, their families, and providers that gives information on each phase of care in the PRC, with recommendations to optimize patient-provider communication and care coordination. The goals of the FCM are to promote mutual trust between the family and PRC clinical team, foster optimal family involvement in care and decision making, promote a timely and satisfactory information transfer between the family and PRC clinical team, and prepare family members for daily life after leaving the PRC. Other organizations that have developed FCMs have reported that they are associated with improved family satisfaction, increased family-centered beliefs and practices among clinical staff, and reduced length of hospital stays [43]. The PRC's FCM uses standardized descriptions of the clinical course and specific 
phases of care, provides a consistent approach and vocabulary to describe the clinical signs for each phase, and describes recommendations for how family members can match their communication and behavior to the current phase of the rehabilitation plan. It is a tool that helps family members participate in the care of their loved one but that also provides clinical staff with standard approaches for addressing the emotional distress and informational needs of family members throughout the episode of care.

\section{Development of Family Care Map}

To ensure that the FCM would be appropriate for the PRCs and meet the identified goals, we organized a "learning collaborative" to plan and develop the map. The collaborative convened a working group (WG) and consensus panel, developed collaborative learning workshops, and initiated both local and overall formative evaluation of the map using iterative plan-do-study-act cycles. Drawing from methods used by other learning collaboratives and FCM projects [43-45], action research [46], and quality improvement [47-48], this collaborative approach has been shown to more likely be adopted and sustained [49-50].

The collaboration charged the WG with identifying the FCM goals that were specific to PRC family needs. The WG identified two goals. Using the FCM, family members should be able to (1) process their reactions to help them cope with the injury, loss, and grief and (2) prepare for recovery within and beyond the PRC. The WG then reviewed the literature on family support; identified other FCMs; interviewed experts in the field, including teams who had previously created FCMs in other healthcare settings; and studied findings from the RAP study and ongoing PRC quality improvement work.

The collaboration convened a consensus panel, made up of a different subset of the learning collaborative members, in 2007. It was charged with recommending the basic components of the FCM. Their recommendations included (1) developing descriptions and definitions of the clinical phases, (2) outlining information for families in each phase, and (3) identifying the key domains for communication and support of family members in each clinical phase. The panel identified resources to support the development of the FCM and then followed up by conducting key informant interviews and focus groups with both family members and PRC clinical staff to obtain feedback and information from stakeholders at their respective sites.
The final FCM has six steps:

1. First contact and introduction: PRC care team.

2. Welcome and settling in to the PRC.

3. Developing a treatment plan.

4. Rehabilitation: Working toward goals.

5. Moving forward.

6. Staying connected.

The Web site includes tabs for information about the polytrauma system of care, polytrauma philosophy of family care, FCM, resources, and frequently asked questions. The FCM includes potentially better practices for each step, a guide for preparing for the eventual transition from the PRC, additional resources, and links to other Web-based resources.

\section{Implementation and Evaluation of Family Care Map}

From October to December 2007, before the FCM's implementation, the collaborative surveyed a convenience sample of PRC clinical staff (nurses, therapists, psychologists, social workers, and physicians) and families of injured patients who were receiving care in the PRC about their satisfaction with current approaches to family care. Overall, 208 clinic staff baseline surveys were sent and over half were returned ( $n=109,52.4 \%)$. Confirming the qualitative findings from the RAP study, 70 percent described their skill level for working with families of patients with polytrauma as fair to poor. Nearly 25 percent were dissatisfied with education materials available for family members, and another 25 percent indicated that they did not have the resources they needed to prepare families for a patient's discharge. Of the family members, 16 also returned FCM satisfaction surveys; the total number of surveys distributed, however, is unknown. Of the 16 responses, more than 30 percent reported that they did not feel adequately prepared to have their family member return home, 50 percent reported not knowing who to call for additional help after discharge, and 53 percent felt they did not have adequate information on followup care after discharge.

In 2008, the collaborative then implemented the FCM at all PRC sites. After 6 months with access to the FCM, we administered postimplementation evaluation surveys to all staff and to families as they prepared for their family member to be discharged from the PRC. These data that are currently being evaluated will be used to adapt and refine the FCM for wider dissemination. 


\section{HOW FAMILIES RESPOND TO STRESS}

Little knowledge still exists about how family members with a loved one suffering from polytrauma alter their lives after the loved one is injured. Previous research confirms that strong cooperation among families is critical in early recovery and rehabilitation of TBI, and little reason exists to doubt this will be true for polytrauma as well. As documented in previous studies of family functioning and rehabilitation outcomes, strong family cooperation can promote successful rehabilitation, while poorly functioning families can actually slow the rehabilitation process [51-53]. Family cooperation, especially over long time periods and in the face of chronic stressors, is often difficult to achieve. Studies suggest that higher levels of perceived family burden and disrupted family functioning are common [51,54]. A number of studies have documented that among married patients with TBI, 30 to 50 percent of marriages dissolved within 10 years posttrauma [6]. Other studies have shown that stress (usually measured as subjective burden) among caregivers of patients with TBI remains high even 10 to 15 years postinjury [6].

Conceptual frameworks used to describe family resiliency may be useful for understanding patients with polytrauma and family members that are at the greatest risk for distress and poor health. Adapted from a large body of work on child resiliency, these frameworks emerged from efforts to understand why some families adapt and thrive in the face of major stressors and disruptions while others do not. The frameworks may be particularly helpful in guiding research on families of patients with polytrauma because they account for both the complexity of families and the course of recovery. In the next subsection, we describe in detail one of the dominant models of family resiliency and follow it with a description of a funded study to examine the characteristics of caregivers of patients with polytrauma, the resources they use to cope with caregiving, and the burden and rewards they find from their unpaid work.

\section{Family Resiliency}

Family resiliency has been conceptualized both as a characteristic of families and as a dynamic process or path a family takes. Extant definitions include, "characteristics, dimensions, and properties of families which help families to be resistant to disruption in the face of change and adaptive in the face of crisis situations” [55, p. 247], "the path a family follows as it adapts and prospers in the face of stress, both in the present and over time” [56, p. 293], and "a dynamic process encompassing positive adaptation within the context of significant adversity” [57].

The dominant model in the field is the Resiliency Model of Family Stress, Adaptation, and Adjustment. It was developed by adapting a stress and coping framework to the study of family resiliency [58-59] and examines family responses to stress in light of the roles played by the family's strengths, resources, and coping mechanisms [55,60]. McCubbin and colleague's research on military families heavily influenced this research, which set out to understand how military families responded to the crises of war [61-63]. They proposed that the existence of family resilience is based on a positive outcome after exposure to a significant stressor. A stressor, such as the burden of caring for a loved one with a traumatic injury, is considered significant if most persons or families exposed to it show symptomatic or dysfunctional behavior or outcomes [64]. As in most stress and coping models, this model focuses on the factors that moderate the relationship between the stressor and some set of family outcomes, and the goal is to identify protective characteristics that buffer families when they are under stress.

McCubbin and colleagues organized protective factors into three overlapping categories [65-66]. They described family protective factors as those that support the family's ability to endure in the face of stressors. Family recovery factors, along with family protective factors, allow a family to bounce back from the adversity or family crisis that initially triggered disorganization or disrupted family functioning. General family resiliency factors support the family's ability to both endure crises and adapt following adversity [55,67]. In addition, family responses are categorized into two distinct phases: "(1) adjustment, which involves the influence of protective factors in facilitating the family's ability and efforts to maintain its integrity, functioning, and fulfill developmental tasks in the face of risk factors, and (2) adaptation, which involves the function of recovery factors in promoting the family's ability to bounce back and adapt in family crisis situations. Consequently, family resilience research has focused on addressing the central and complex issues of determining what protective factors are critical to family adjustment in the face of specific risks or cluster of risk factors, as well as what recovery factors 
are critical to family adaptation in the face of specific family crisis situations" [65].

\section{Current Efforts to Understand Outpatient Caregiver and Family Experiences}

To date, little knowledge exists about who is providing ongoing and informal (unpaid) care to patients with polytrauma, how much and what kind of care is required, how to best prepare family caregivers for the role, or how the challenges of caregiving affect caregiver health and patient rehabilitation in the short and long term. Although some studies exist describing the demands faced by families of patients with TBI during acute rehabilitation and after discharge [6], few examine the long-term effects of caregiving [6,37]. Moreover, we have little information on important family resiliency factors or family protective and recovery factors after traumatic injuries. Thus, we currently have no basis to make informed choices regarding where the greatest need for interventions is or what the most appropriate intervention objectives are. To address these gaps, we are conducting a study of family caregivers of all patients who have been discharged from a VA PRC. Using mailed surveys, the study quantitatively describes and assesses the physical, emotional, and financial burden of caregiving and the resources available to caregivers and tests how strain from the burden of caregiving is associated with caregiver and patient mental and physical health and family discord. Following the mailed survey, researchers will purposively sample 16 caregivers (based on sex and familial relationship to patient) who participated in the mailed survey and conduct in-depth interviews to provide a contextual understanding of caregiving to interpret survey results. Interviews will also help uncover additional content areas and inform the selection of future interventions.

This study will contribute to the knowledge base in several ways. First, although ample evidence exists that caring for a patient with TBI is burdensome for caregivers, such evidence is based for the most part on studies relying on caregiver-patient participants during acute inpatient rehabilitation and recent discharge. This study will expand our understanding of the factors that contribute to caregiver burden by including caregivers of patients who have a range of intervals since discharge (anywhere from 3 months to several years postinjury). Second, this research will also fill an unacceptable gap in our knowledge regarding the associations between caregiver outcomes and outcomes of patients with polytrauma. This knowledge is likely to be applicable to other rehabilitation patients, such as those with spinal cord injury and stroke, who often require long-term caregiving with complicated care tasks. Third, although this study is currently cross-sectional and, therefore, can test for association but not for directions of causality, it will create a cohort that can be followed longitudinally to test causal hypotheses. Finally, the study will lay the foundation for caregiver intervention programs that could be implemented by the VA's Vocational Rehabilitation and Employment (VR\&E) service, Veterans Benefits Administration (VBA), and offices and programs within the Veterans Health Administration (VHA), including the VA Office of Care Coordination, the Patient Care Services Task Force, and the PRCs.

\section{FUTURE DIRECTIONS FOR RESEARCH}

\section{Additional Gaps}

While steps are currently in place to build an evidence base to understand how families function and adapt to their loved one's polytrauma, little knowledge exists about how the changes in clinical practice and long-term care will affect patients and families. In this rapidly changing area, concerted efforts to address these issues and rapid dissemination of key findings are critical to provide optimal and efficient support for family caregivers of servicemembers with polytrauma. We have identified a range of areas in the inpatient and outpatient settings in which limited research exists for families of those with TBI and is nonexistent for families of patients with polytrauma. Understanding many of these issues will help inform the DOD, VA (including VHA, VBA, and VR\&E), and community leaders (e.g., local ministers, mental health workers, employers) of how benefits and resources affect families and help researchers and clinicians plan for appropriate interventions.

\section{Training}

As other studies have shown, training programs to improve the clinical, management, and emotional skills often needed to provide informal care may also improve quality of life and the health of family caregivers and their care recipients [68-69]. Most of these studies, however, have been limited to caregiving of patients with dementia. Training will likely help improve the skills for caregivers of patients with polytrauma, but the specific components that will be most appropriate and effective 
for training are unclear, given the complexity of polytraumatic injuries and their residual effects. Additional research is needed to determine the key components for training and to test their effectiveness.

\section{Communication and Information Needs for Families and Providers}

Identifying what clinical, vocational, legal, and benefits resources are needed for families throughout the course of care and communicating how best to access those resources are critical for assisting families and patients to become more independent. Identifying more specific communication strategies for providers, such as how to balance patient privacy concerns with family care objectives, how to assist families as they navigate the legal and benefit systems, and how to communicate with multiple family systems, is also essential to identify key areas for interventions. Understanding whether these strategies improve family and patient outcomes in the short and long term would likely have broad implications for changes in clinical practice.

\section{Financial Impact of Caregiving}

Throughout the stages of recovery and rehabilitation, families often incur direct and indirect costs associated with providing care. These costs may escalate substantially once a servicemember is discharged from the hospital or inpatient rehabilitation center. Because informal care often offsets formal inpatient and outpatient care, understanding the costs of care, both financial and lost opportunity costs, is necessary to provide greater insight into the short- and long-term effects of providing care.

\section{Changing Families}

Family roles often change, just as injured servicemember's roles change over time. Likewise, families will age, just as these servicemembers will. Because family members often play key roles in navigating services, benefits, and resources for injured veterans, understanding the effect that providing care has on families as they change and age will be critical. This understanding includes specific periods of transition, such as how families cope with the transition from military to civilian culture or from inpatient acute rehabilitation to home. It also includes broader, long-term issues, such as how marriages and relationships change over time, how children are affected by caregiving, and how caregiving roles and caregiving tasks change as family members age.

\section{Attitudes and Beliefs About Treatment for Residual Effects}

Pain, depression, and anger are often long-term residual effects of traumatic injuries. Previous studies have shown that caregivers' emotional appraisals of and beliefs about a family member's condition can affect clinical outcomes [70]. Beliefs among caregivers of patients with cancer, for example, have shown that family attitudes about long-term pain management can affect patient reports of pain [7172]. Little knowledge exists, however, about family attitudes and beliefs about long-term treatment for people who have experienced polytrauma. We need information to adequately assess, treat, and manage the unique effects associated with polytrauma in a culturally appropriate manner.

\section{Access to Services}

Navigating systems of care, services, and benefits is a common source of stress for families, especially for those who are socially and geographically isolated. Technological innovations such as teleconferencing and Internet messaging are better studied in other areas, such as chronic-disease monitoring [73-74]. They provide a promising approach, however, for long-term care and support for families by bridging barriers due to geography, lack of specialty care, or lack of supportive social networks among families in similar situations [75-76]. Research testing whether these systems are effective for improving family functioning and patient outcomes could provide valuable lessons, not only for families with an injured family member but also for families who have loved ones with chronic or disabling conditions.

\section{Psychosocial Adjustment}

Family members and caregivers often have questions about the effect of their family member's injuries on their own psychological and emotional health, but little research exists to determine how much these concerns affect family functioning. For instance, issues of intimacy with the injured family member, grief and loss over the new physical and behavioral changes in their injured family member, and experiences with stigma and discrimination are common concerns for those injured and family members, but little work exists to determine if and how they affect short- and long-term coping and functioning.

\section{CONCLUSIONS}

These areas are just a sample of the many unresolved questions that researchers and policy makers need to 
undertake to address how to adequately support families and servicemembers with polytrauma. Understanding many of these issues will help better inform family members of policies for benefits and resources affecting families and help researchers and clinicians plan appropriate interventions.

\section{ACKNOWLEDGMENTS}

\author{
Author Contributions: \\ Study concept and design: J. M. Griffin, G. Friedemann-Sánchez, \\ C. Hall, S. Phelan, M. van Ryn. \\ Drafting of manuscript: J. M. Griffin, G. Friedemann-Sánchez, \\ C. Hall, M. van Ryn, S. Phelan. \\ Critical revision of manuscript for important intellectual content: \\ J. M. Griffin, G. Friedemann-Sánchez, C. Hall, M. van Ryn, S. Phelan. \\ Study supervision: J. M. Griffin. \\ Financial Disclosures: The authors have declared that no competing \\ interests exist. \\ Funding/Support: This material was based on work supported by VA \\ Health Services Research and Development Service (grants RRP 06- \\ 149 and SDR 07-044) and the VA PT/BRI QUERI. \\ Additional Contributions: Mr. Phelan is now with the Center for \\ Chronic Disease Outcomes Research, VA Health Services Research \\ and Development Center of Excellence, VA Medical Center, Minne- \\ apolis, Minnesota.
}

\section{REFERENCES}

1. DOD: Press resources [Internet]. Washington (DC): Department of Defense; 2009. Casualty update; 2009 Sep 14 [cited 2008 Dec 30]; [1 screen]. Available from: http://www.defenselink.mil/news/casualty.pdf/.

2. Sayer NA, Chiros CE, Sigford B, Scott S, Clothier B, Pickett T, Lew HL. Characteristics and rehabilitation outcomes among patients with blast and other injuries sustained during the Global War on Terror. Arch Phys Med Rehabil. 2008;89(1):163-70. [PMID: 18164349] DOI:10.1016/j.apmr.2007.05.025

3. Okie S. Traumatic brain injury in the war zone. N Engl $\mathrm{J}$ Med. 2005;352(20):2043-47. [PMID: 15901856] DOI:10.1056/NEJMp058102

4. Warden DL, French L. Traumatic brain injury in the war zone. N Engl J Med. 2005;353(6):633-34.

[PMID: 16094767] DOI:10.1056/NEJM200508113530621

5. Fakhry SM, Trask AL, Waller MA, Watts DD; IRTC Neurotrauma Task Force. Management of brain-injured patients by an evidence-based medicine protocol improves outcomes and decreases hospital charges. J Trauma. 2004;
56(3):492-500. [PMID: 15128118$]$

DOI:10.1097/01.TA.0000115650.07193.66

6. Verhaeghe S, Defloor T, Grypdonck M. Stress and coping among families of patients with traumatic brain injury: A review of the literature. J Clin Nurs. 2005;14(8):1004-12. [PMID: 16102152] DOI:10.1111/j.1365-2702.2005.01126.x

7. Gordon WA, Zafonte R, Cicerone K, Cantor J, Brown M, Lombard L, Goldsmith R, Chandna T. Traumatic brain injury rehabilitation: State of the science. Am J Phys Med Rehabil. 2006;85(4):343-82. [PMID: 16554685] DOI:10.1097/01.phm.0000202106.01654.61

8. Caron W, Boss P, Mortimer J. Family boundary ambiguity predicts Alzheimer's outcomes. Psychiatry. 1999;62(4): 347-56. [PMID: 10693231]

9. Evans RL, Bishop DS, Haselkorn JK. Factors predicting satisfactory home care after stroke. Arch Phys Med Rehabil. 1991;72(2):144-47. [PMID: 1991016]

10. Friedemann-Sánchez G, Sayer NA, Pickett T. Provider perspectives on the rehabilitation of patients with polytrauma. Arch Phys Med Rehabil. 2008;89(1):171-78.

[PMID: 18164350]

DOI:10.1016/j.apmr.2007.10.017

11. Sigford BJ. "To care for him who shall have borne the battle and for his widow and his orphan" (Abraham Lincoln): The Department of Veterans Affairs Polytrauma System of Care. Arch Phys Med Rehabil. 2008;89(1):160-62.

[PMID: 18164348]

DOI:10.1016/j.apmr.2007.09.015

12. Veterans Health Administration. Polytrauma rehabilitation procedures. VHA Handbook 1172.1. Washington (DC): Department of Veterans Affairs; 2005.

13. Coon DW, Rubert M, Solano N, Mausbach B, Kraemer H, Arguëlles T, Haley WE, Thompson LW, Gallagher-Thompson D. Well-being, appraisal, and coping in Latina and Caucasian female dementia caregivers: Findings from the REACH study. Aging Ment Health. 2004;8(4):330-45.

[PMID: 15370049]

DOI:10.1080/13607860410001709683

14. Gottlieb BH, Rooney JA. Coping effectiveness: Determinants and relevance to the mental health and affect of family caregivers of persons with dementia. Aging Ment Health. 2004;8(4):364-73. [PMID: 15370052] DOI:10.1080/13607860410001709719

15. Burr G. Contextualizing critical care family needs through triangulation: An Australian study. Intensive Crit Care Nurs. 1998;14(4):161-69. [PMID: 9849242] DOI:10.1016/S0964-3397(98)80473-4

16. Chiu YL, Chien WT, Lam LW. Effectiveness of a needsbased education programme for families with a critically ill relative in an intensive care unit. J Clin Nurs. 2004;13(5): 
655-56. [PMID: 15189419]

DOI:10.1111/j.1365-2702.2004.00844.X

17. Davis-Martin S. Perceived needs of families of long-term critical care patients: A brief report. Heart Lung. 1994;23(6): 515-18. [PMID: 7852067]

18. Ward K. Perceived needs of parents of critically ill infants in a neonatal intensive care unit (NICU). Pediatr Nurs. 2001; 27(3):281-86. [PMID: 12964668]

19. Spatt L, Ganas E, Hying S, Kirsch ER, Koch M. Informational needs of families of intensive care unit patients. QRB Qual Rev Bull. 1986;12(1):16-21. [PMID: 3083317]

20. Verhaeghe S, Defloor T, Van Zuuren F, Duijnstee M, Grypdonck $\mathrm{M}$. The needs and experiences of family members of adult patients in an intensive care unit: A review of the literature. J Clin Nurs. 2005;14(4):501-9.

[PMID: 15807758]

DOI:10.1111/j.1365-2702.2004.01081.x

21. Friedemann-Sánchez G, Griffin JM, Rettmann N, Rittman M, Partin MR. Communicating information to families of polytrauma patients: Narrative literature review. Rehabil Nurs. 2008;33(5):206-13. [PMID: 18767402]

22. Armstrong K, Kerns KA. The assessment of parent needs following paediatric traumatic brain injury. Pediatr Rehabil. 2002;5(3):149-60. [PMID: 12581477]

DOI:10.1080/1363849021000039353

23. Engli M, Kirsivali-Farmer K. Needs of family members of critically ill patients with and without acute brain injury. J Neurosci Nurs. 1993;25(2):78-85. [PMID: 8478558]

24. Kreutzer JS, Serio CD, Bergquist S. Family needs after brain injury: A quantitative analysis. J Head Trauma Rehabil. 1994;9:104-15.

DOI:10.1097/00001199-199409000-00009

25. Meade MA, Taylor LA, Kreutzer JS, Marwitz JH, Thomas V. A preliminary study of acute family needs after spinal cord injury: Analysis and implications. Rehabil Psychol. 2004;49(2):150-55. DOI:10.1037/0090-5550.49.2.150

26. Aitken ME, Mele N, Barrett KW. Recovery of injured children: Parent perspectives on family needs. Arch Phys Med Rehabil. 2004;85(4):567-73. [PMID: 15083431] DOI:10.1016/j.apmr.2003.06.018

27. Bond AE, Draeger CR, Mandleco B, Donnelly M. Needs of family members of patients with severe traumatic brain injury. Implications for evidence-based practice. Crit Care Nurse. 2003;23(4):63-72. [PMID: 12961784]

28. Ramritu PL, Croft G. Needs of parents of the child hospitalised with acquired brain damage. Int J Nurs Stud. 1999; 36(3):209-16. [PMID: 10404290] DOI:10.1016/S0020-7489(99)00016-4

29. Holland D, Shigaki CL. Educating families and caretakers of traumatically brain injured patients in the new health care environment: A three phase model and bibliography.
Brain Inj. 1998;12(12):993-1009. [PMID: 9876860]

DOI:10.1080/026990598121918

30. Degeneffe CE. Family caregiving and traumatic brain injury. Health Soc Work. 2001;26(4):257-68.

[PMID: 11758867]

31. Junqué C, Bruna O, Mataró M. Information needs of the traumatic brain injury patient's family members regarding the consequences of the injury and associated perception of physical, cognitive, emotional and quality of life changes. Brain Inj. 1997;11(4):251-58. [PMID: 9134199] DOI:10.1080/026990597123557

32. Sinnakaruppan I, Williams DM. Family carers and the adult head-injured: A critical review of carers' needs. Brain Inj. 2001;15(8):653-72. [PMID: 11485607] DOI:10.1080/02699050010025759

33. Morris KC. Psychological distress in carers of head injured individuals: The provision of written information. Brain Inj. 2001;15(3):239-54. [PMID: 11260772] DOI:10.1080/02699050010004068

34. Paterson B, Kieloch B, Gmiterek J. "They never told us anything:" Postdischarge instruction for families of persons with brain injuries. Rehabil Nurs. 2001;26(2):48-53. [PMID: 12035699]

35. Holland D, Holland D. Children's health promotion through caregiver preparation in pediatric brain injury settings: Compensating for shortened hospital stays with a three-phase model of health education and annotated bibliography. Issues Compr Pediatr Nurs. 2002;25(2):73-96.

[PMID: 12060516] DOI:10.1080/01460860290042512

36. Testani-Dufour L, Chappel-Aiken L, Gueldner S. Traumatic brain injury: A family experience. J Neurosci Nurs. 1992;24(6):317-23. [PMID: 1289428]

37. Vaccaro MJ, Hart T, Whyte J. Internet resources for traumatic brain injury: A selective review of websites for consumers. NeuroRehabilitation. 2002;17(2):169-74. [PMID: 12082244$]$

38. Levine C. Rough crossings: Family caregiver odysseys through the health care system. New York (NY): United Hospital Fund of New York; 1998.

39. Bamm EL, Rosenbaum P. Family-centered theory: Origins, development, barriers, and supports to implementation in rehabilitation medicine. Arch Phys Med Rehabil. 2008; 89(8):1618-24. [PMID: 18586223]

DOI:10.1016/j.apmr.2007.12.034

40. Rosenbaum P, King S, Law M, King G, Evans J. Familycentered service: A conceptual framework and research review. Phys Occup Ther Pediatr. 1998;18(1):1-20.

DOI:10.1300/J006v18n01 01

41. King G, Kertoy M, King S, Law M, Rosenbaum P, Hurley P. A measure of parents' and service providers' beliefs about participation of family-centered services. Child Health 
Care. 2003;32(3):191-214.

DOI:10.1207/S15326888CHC3203 2

42. King S, King G, Rosenbaum P. Evaluating health service delivery to children with chronic conditions and their families: Development of a refined Measure of Processes of Care (MPOC-20). Child Health Care. 2004;33(1):35-57. DOI:10.1207/s15326888chc3301 3

43. Dunn MS, Reilly NC, Johnstone AM, Hoopes RD Jr, Abraham MR. Development and dissemination of potentially better practices for the provision of family-centered care in neonatology: The family-centered care map. Pediatrics. 2006;118(Suppl 2):S95-107. [PMID: 17079629] DOI:10.1542/peds.2006-0913F

44. Horbar JD, Carpenter JH, Buzas J, Soll RF, Suresh G, Bracken MB, Leviton LC, Plsek PE, Sinclair JC. Collaborative quality improvement to promote evidence based surfectant for preterm infants: A cluster randomised trial. BMJ. 2004;329(7473):1004. [PMID: 15514344]

DOI:10.1136/bmj.329.7473.1004

45. Horbar JD, Plsek PE, Leahy K. NIC/Q 2000: Establishing habits for improvement in neonatal intensive care units. Pediatrics. 2003;111(4 Pt 2):e397-410. [PMID: 12671159]

46. Stringer ET. Action research: A handbook for practitioners. 2nd ed. Thousand Oaks (CA): Sage Publications; 1999.

47. Langley GL, Nolan KM, Nolan TW, Norman CL, Provost LP. The improvement guide: A practical approach to enhancing organizational performance. San Francisco (CA): Jossey-Bass Publishers; 1996.

48. Institute for Healthcare Improvement. The breakthrough series: IHI's collaborative model for achieving breakthrough improvement. Cambridge (MA): Institute for Healthcare Improvement; 2003.

49. Chin MH, Drum ML, Guillen M, Rimington A, Levie JR, Kirchhoff AC, Quinn MT, Schaefer CT. Improving and sustaining diabetes care in community health centers with the health disparities collaboratives. Med Care. 2007;45(12): 1135-43. [PMID: 18007163] DOI:10.1097/MLR.0b013e31812da80e

50. Lesar TS, Anderson ER Jr, Fields J, Saine D, Gregoire J, Fraser S, Parkin M, Mattis A; VHA New England Medication Error Prevention Initiative. The VHA New England Medication Error Prevention Initiative as a model for longterm improvement collaboratives. Jt Comm J Qual Patient Saf. 2007;33(2):73-82. [PMID: 17370918]

51. Sander AM, Caroselli JS, High WM Jr, Becker C, Neese L, Scheibel R. Relationship of family functioning to progress in a post-acute rehabilitation programme following traumatic brain injury. Brain Inj. 2002;16(8):649-57.

[PMID: 12182162]

DOI:10.1080/02699050210128889

52. Groom KN, Shaw TG, O’Connor ME, Howard NI, Pickens A. Neurobehavioral symptoms and family functioning in traumatically brain-injured adults. Arch Clin Neuropsychol. 1998;13(8):695-711. [PMID: 14590629]

53. Van Baalen B, Ribbers GM, Medema-Meulepas D, Pas MS, Odding E, Stam HJ. Being restricted in participation after a traumatic brain injury is negatively associated by passive coping style of the caregiver. Brain Inj. 2007; 21(9):925-31. [PMID: 17729045]

DOI:10.1080/02699050701553197

54. Taylor H, Drotar D, Wade S, Yeates K, Stancin T, Klein S. Recovery from traumatic brain injury in children: The importance of the family. In: Broman SH, Michel ME, editors. Traumatic head injury in children. New York (NY): Oxford University Press; 1995.

55. McCubbin HI, McMubbin MA. Typologies of resilient families: Emerging roles of social class and ethnicity. Fam Relat. 1988;37(3):247-54. DOI:10.2307/584557

56. Hawley DR, DeHaan L. Toward a definition of family resilience: Integrating life-span and family perspectives. Fam Process. 1996;35(3):283-98. [PMID: 9111710] DOI:10.1111/j.1545-5300.1996.00283.x

57. Luthar SS, Cicchetti D. The construct of resilience: Implications for interventions and social policies. Dev Psychopathol. 2000;12(4):857-85. [PMID: 11202047]

58. McCubbin HI, McCubbin MA. Family stress theory and assessment: The T-double ABCX model of family adjustment and adaptation. In: McCubbin HI, Thompson AI, editors. Family assessment for research and practice. Madison (WI): University of Wisconsin-Madison; 1987. p. 3-34.

59. McCubbin HI, Patterson JM. The family stress process: The double ABCX model of adjustment and adaptation. Marriage Fam Rev. 1983;6(1):7-37.

DOI:10.1300/J002v06n01 02

60. McCubbin HI, Thompson EA, Thompson AI, Fromer JE, editors. Resiliency in African American families. Thousand Oaks (CA): Sage Publications; 1998.

61. McCubbin HI, Boss P, Wilson L, Lester G. Developing family invulnerability to stress: Coping patterns and strategies wives employ. In: Trost J, editor. The family and change. Sweden: International Library; 1980. p. 89-103.

62. McCubbin HI, Patterson JM. Family adaptation to crises. In: McCubbin HI, Cauble AE, Patterson JM, editors. Family stress, coping, and social support. Springfield (IL): Thomas; 1982.

63. McCubbin HI, Dahl BB, Lester GR, Ross BA. The returned prisoners of war: Factors in family reintegration. J Marriage Fam. 1975;73(3):471-78. DOI:10.2307/350511

64. Patterson JM. Integrating family resilience and family stress theory. J Marriage Fam. 2002;64(2):349-60. DOI:10.1111/j.1741-3737.2002.00349.x

65. McCubbin HI, McCubbin MA, Thompson AI, Han SY, Allen CT. Families under stress: What makes them resilient. 
American Association of Family and Consumer Sciences Commemorative Lecture; 1997 Jun 22; Washington, DC.

66. McCubbin HI, Thompson EA, Thompson AI, Fromer JE, editors. Resiliency in Native American and immigrant families. Thousand Oaks (CA): Sage Publications; 1998.

67. McCubbin HI, Thompson EA, Thompson AI, Futrel JA, editors. The dynamics of resilient families. Thousand Oaks (CA): Sage Publications; 1999.

68. Sörensen S, Pinquart M, Duberstein P. How effective are interventions with caregivers? An updated meta-analysis. Gerontologist. 2002;42(3):356-72. [PMID: 12040138]

69. Belle SH, Burgio L, Burns R, Coon D, Czaja SJ, GallagherThompson D, Gitlin LN, Klinger J, Koepke KM, Lee CC, Martindale-Adams J, Nichols L, Schulz R, Stahl S, Stevens A, Winter L, Zhang S; Resources for Enhancing Alzheimer's Caregiver Health (REACH) II Investigators. Enhancing the quality of life of dementia caregivers from different ethnic or racial groups: A randomized, controlled trial. Ann Intern Med. 2006;145(10):727-38. [PMID: 17116917]

70. Wearden AJ, Tarrier N, Barrowclough C, Zastowny TR, Rahill AA. A review of expressed emotion research in health care. Clin Psychol Rev. 2000;20(5):633-66. [PMID: 10860170] DOI:10.1016/S0272-7358(99)00008-2

71. Pargeon KL, Hailey BJ. Barriers to effective cancer pain management: A review of the literature. J Pain Symptom
Manage. 1999;18(5):358-68. [PMID: 10584460]

DOI:10.1016/S0885-3924(99)00097-4

72. Taylor EJ, Ferrel BR, Grant M, Cheyney L. Managing cancer pain at home: The decisions and ethical conflicts of patients, family caregivers, and homecare nurses. Oncol Nurs Forum. 1993;20(6):919-27. [PMID: 8367345]

73. Bensink M, Hailey D, Wootton R. A systematic review of successes and failures in home telehealth: Preliminary results. J Telemed Telecare. 2006;12(Suppl 3):8-16. DOI:10.1258/135763306779380174

74. Darkins A. Changing the location of care: Management of patients with chronic conditions in Veterans Health Administration using care coordination/home telehealth. J Rehabil Res Dev. 2006;43(4):vii-xii. [PMID: 17123179] DOI:10.1682/JRRD.2006.03.0029

75. Buckley KM, Tran BQ, Prandoni CM. Receptiveness, use and acceptance of telehealth by caregivers of stroke patients in the home. Online J Issues Nurs. 2004;9(3):9. [PMID: 15482095$]$

76. Rotondi AJ, Sinkule J, Spring M. An interactive web-based intervention for persons with TBI and their families: Use and evaluation by female significant others. J Head Trauma Rehabil. 2005;20(2):173-85. [PMID: 15803040] DOI:10.1097/00001199-200503000-00005

Submitted for publication August 19, 2008. Accepted in revised form January 20, 2009. 